\title{
Práticas de violências na fronteira: estudo sobre os garimpos de diamante em Juína, MT (1987-1994)
}

\author{
Las prácticas violencias en la frontera: estudio sobre los garimpos \\ de diamante en Juína, MT (1987-1994)
}

The frontier violence practices: study on diamond mining in Juína, MT (1987-1994)

Vitale Joanoni Neto*

Júlio Cesardos Santos ${ }^{* * *}$

\section{Resumo}

Este artigo realiza uma discussão inicial acerca das relações de poder e da violência nas áreas de fronteira reocupadas por diferentes grupos sociais, tais como mineradores tradicionais, prostitutas, peões e comerciantes, nos espaços dos garimpos, constituídos a partir das descobertas de jazidas diamantíferas no município de Juína, Noroeste de Mato Grosso, Brasil, entre os anos de 1987 e 1994. O poder é compreendido como relação legítima de comando e obediência, ao passo que violência é pensada como instrumento de dominação e imposição sobre o outro em locais cuja presença do Estado é incipiente. Weber e Arendt são importantes referências para o diálogo da relação entre poder e violência. A fronteira é pensada na lógica das fren- tes de expansão e pioneirismo de José de Souza Martins. O recurso da história oral foi utilizado para recuperar relatos de violência nesses espaços, em especial no Garimpo do Arroz.

Palavras-chave: Fronteira. Garimpos. Violência.

* Doutor em História pela Universidade Estadual Paulista Júlio de Mesquita Filho. Professor associado da Universidade Federal de Mato Grosso. E-mail: vitalejneto@gmail.com

** Doutor em História pela Universidade Federal de Mato Grosso. Docente do Instituto Federal de Mato Grosso - Campus de Alta Floresta. E-mail: julio.santos@alf.ifmt.edu.br

Recebido em: 21/12/2017 - Aprovado em: 22/02/2018 http://dx.doi.org/10.5335/hdtv.18n.2.8072 
Neste artigo, pretendemos analisar algumas práticas de violência verificadas em áreas de garimpo no noroeste do estado de Mato Grosso, entre 1987 e 1994, quando apareceram os principais focos de exploração de diamante, que tornaram Juína referência mundial de produção e comércio. $\mathrm{O}$ objetivo é analisar os elementos que distinguem essas práticas de violência, entendendo-as como indissociáveis das estratégias do Estado civil-militar, que olhou de modo privilegiado para a Amazônia meridional, como lócus das políticas da denominada integração nacional. O Estado civil-militar foi incapaz de estabelecer um mínimo controle sobre as ações de reocupação, tal como havia nos grandes centros urbanos durante o auge de sua fase repressiva com uma rede de informação. Nas áreas de fronteira, os poucos agentes públicos, ligados ao Instituto Nacional de Colonização e Reforma Agrária (Incra), ao extinto Instituto Brasileiro de Desenvolvimento Florestal (IBDF), à Fundação Nacional do Índio (Funai) ou ao Departamento Nacional de Produção Mineral (DNPM), foram incapazes de qualquer controle ou mesmo acesso a essas áreas para as quais se dirigiam os migrantes de todas as partes do Brasil, atraídos pela propaganda que apresentava a Amazônia como a terra da promissão.

Diante de um discurso que afirmou a "ausência do Estado", as prerrogativas de controle sobre os grupos sociais que se organizavam nesses novos locais ficaram nas mãos de grandes fazendeiros, empresários rurais, capatazes, gerentes ou administradores dos empreendimentos que se estabeleciam sobre as terras de grupos indígenas, posseiros, pequenos proprietários. Foi nesse contexto que surgiram as práticas de pistolagem, grilagem de terras e desmatamento ilegal, amparadas em um discurso que classificava esses empreendimentos e seus proponentes como instrumentos para promover o desenvolvimento da Amazônia.

Nas áreas de garimpo, esse controle escapou mesmo desses mandantes locais. Nas currutelas - locais em que se fixavam os garimpeiros - e nas áreas de exploração, verificamos uma inversão em relação aos propósitos dos migrantes pequenos produtores ou trabalhadores rurais. Para esses últimos, esses novos locais eram destino, terra prometida, lugar de moradia. Para os garimpeiros, era ponto de passagem. Sua permanência está condicionada ao sucesso imediato na busca do minério. Nada se preserva, nada se poupa, nem suas vidas. Amizades e relacionamentos eram momentâneos, e disputas, rixas, desentendimentos, com frequência, eram resolvidos com o uso da violência.

Tal violência deve ser sempre compreendida como um fenômeno social, inserido em um determinado contexto e concretizado em uma modalidade possível de interação relacional entre diferentes (CAMPOS; GUIMARÃES, 2008, p. 902). Sua polissemia pode ser melhor entendida dentro das escalas próprias de valores sociais, ou seja, podemos caracterizar um ato como violento quando uma ação direta ou indireta causa danos a um indivíduo ou grupo, seja física, moral ou economicamente (MICHAUD, 1989, p. 10). Logo, segundo a escala de valores das sociedades ocidentais, entende-se como violenta a intervenção física de um indivíduo ou grupo contra outro indivíduo 
ou grupo (ou contra si mesmo): “Exerce violência quem tortura, fere ou mata, quem não obstante a resistência, imobiliza ou manipula o corpo do outro; quem impede materialmente outro de cumprir determinada ação [...]. A violência pode ser direta ou indireta" (OBBIO, 1993, p. 1291).

A violência existe em meio aos homens, somos os responsáveis por ela, e quando pensamos pelo lado daquele que a pratica, corremos o risco de legitimá-la, justificando os meios pelos fins, logo, visando evitar tal erro, devemos inicialmente defini-la pelo lado daquele que sofre a ação violenta (MÜLLER, 2007, p. 30). Isso porque, uma vez legitimada, perdemos a capacidade de exercer controle sobre a própria violência, perdemos todos os limites, em suma, passamos a julgar não a violência, mas a representação que fazemos dela, e ela sempre aparecerá como meio legítimo para o combate às injustiças que, aos nossos olhos, são praticadas.

Pessoas comuns, para desincumbir-se de uma tarefa, podem agir de modo violento ou atroz, mesmo quando os efeitos de sua atrocidade já não podem mais ser ignorados. As regras sociais e os fundamentos básicos da moral não oferecem resistência suficiente para impedir tais ações. Exemplo disso é o caso narrado por Hannah Arendt (1999) acerca do julgamento de Adolf Eichmann, um oficial do exército alemão com atribuições burocráticas ligadas ao aparelho de extermínio de judeus criado pelo III Reich. Segundo Arendt (1999), Eichmann não possuía um histórico ou traços antissemitas, não apresentava características de uma pessoa com caráter distorcido ou doentio. Ele agiu como agiu por desejo de ascender em sua carreira profissional, e seu atos foram resultado de cumprimento de ordens superiores. Ele era um burocrata que cumpria ordens sem racionalizar suas consequências. Para Ele, tudo era realizado com zelo e eficiência, e não havia o sentimento de "bem" ou o de "mal" em seus atos. Arendt não o vê como um "monstro". Os atos de Eichmann não eram desculpáveis e nem ele era inocente, mas esses atos não foram realizados por um ser dotado de imensa capacidade de crueldade, e sim por um funcionário burocrata, dentro de um sistema baseado em atos de extermínio. Foi a partir desta análise que ela cunhou a expressão "banalidade do mal" para indicar que alguns indivíduos agem dentro das regras do sistema a que pertencem, sem racionalizar sobre seus atos. Eles não se preocupam com as consequências, só com o cumprimento das ordens. A tortura, a execução de seres humanos ou a prática de tais atos não são racionalizadas em seu resultado final, desde que as ordens para executá-las advenham de instâncias superiores.

Arendt (2009, p. 23) afirma que, em nossa sociedade, tomamos certos atos arbitrários como corriqueiros, portanto os desconsideramos ou não os questionamos, pois os tomamos como óbvios. Para o nosso caso em análise, a autora assume especial importância também quando separa poder e violência em campos opostos: "um domina absolutamente, o outro está ausente" (ARENDT, 2009, p. 73). Logo, onde incide a violência, o poder não se evidencia, pois o lugar ocupado por um suprime consequentemente o do outro. Em sua análise, a autora estabelece as diferenças entre poder, violên- 
cia, vigor, força e autoridade: "O poder corresponde à habilidade humana não apenas para agir, mas também para agir em concerto. O poder nunca é propriedade de um indivíduo; pertence a um grupo e permanece em existência apenas enquanto o grupo se conserva unido" (ARENDT, 2009, p. 60). Poder, na visão de Arendt, tem uma relação fundamental com o fenômeno da liberdade, a qual é caracterizada pela participação efetiva na vida pública, ou seja, o ato de exercer o diálogo para a constituição de uma sociedade livre. $\mathrm{O}$ vigor assinala algo singular, é propriedade essencial de um objeto ou pessoa e pertencente ao seu caráter: “[...] é da natureza de um grupo e de seu poder voltar-se contra a independência, a propriedade do vigor individual" (ARENDT, 2009, p. 61). Podemos caracterizar o vigor como algo individual, que pode relacionar-se como força física e mental, cuja dimensão modifica muito de pessoa para pessoa. $\mathrm{O}$ vigor é uma liderança que acontece naturalmente, não é coagida, nem condicionada. $\mathrm{O}$ dominador tem vigor porque traz consigo a habilidade para o comando.

Em seu uso corrente, quando falamos de um "homem poderoso" ou de uma "personalidade poderosa", já usamos a palavra "poder" metaforicamente; aquilo a que nos referimos sem metáfora é "vigor" (ARENDT, 2009, p. 61).

O fenômeno da autoridade também é comumente confundido com a violência. "Sua insígnia é o reconhecimento inquestionável daqueles a quem se pede que obedeçam; nem a coerção nem a persuasão são necessárias" (ARENDT, 2009, p. 62). Contudo, podemos verificar que a violência obtém a sujeição por meio da repressão, e o poder, pela persuasão; já a autoridade renuncia a ambos, pois provém da obediência reconhecida pela hierarquia ocupada por cada indivíduo, em um lugar estável predeterminado. Por sempre exigir obediência, a autoridade é comumente confundida com alguma forma de poder ou violência. Entretanto, a autoridade exclui a utilização de meios externos de coerção. Quando a força é usada, a autoridade em si fracassa, pois ela é incompatível com persuasão, pressupõe igualdade e opera mediante um processo de argumentação (ARENDT, 2001, p. 129).

A violência se apoia no uso da força, provoca o medo e impõe a obediência, mas isso, por si, não constitui um Estado (ou sua presença), por vezes, não é mais que demonstração de vigor individual. A violência é instrumental. Do cano de uma arma, ela pode apenas se reproduzir, nunca produzir o poder institucionalizado. Essa violência de caráter instrumental foi utilizada para impor as "novas" relações empresariais, para o emprego da prática do trabalho escravo no interior das fazendas.

O estabelecimento das empresas agropecuárias e de colonização no Mato Grosso foi fruto dos projetos incentivados pelo governo civil-militar para a modernização, o desenvolvimento e o progresso da Amazônia, política que custou a vida de muitos trabalhadores, índios e posseiros, como também causou a exclusão e marginalização da população local, violentou e eliminou todos os seus direitos sob o aval dos governantes daquele momento, sempre afirmando a sua esperança em um futuro melhor proporcionado pelo aparecimento do novo modo de vida. 
Juína, na segunda década do século XXI, era uma cidade considerada polo regional. Localizada no noroeste do estado de Mato Grosso, surgiu no final da década de 1970, a partir de um projeto de colonização executado pela Companhia de Desenvolvimento de Mato Grosso (Codemat), empresa estatal de capital aberto criada em 1968, no então município de Aripuanã. Juína foi um dos 289 projetos de colonização criados nas décadas de 1970 e 1980 pelo Estado civil-militar, majoritariamente entregues a empresas privadas, com vistas a promover a reocupação e o desenvolvimento das fronteiras da Amazônia e aliviar as tensões sociais das regiões Sul e Sudeste do país (MORENO, 1999, p. 81). Essas ações, na verdade grandes empreendimentos imobiliários, foram chamadas de projetos de colonização, quando a terra foi entregue a uma empresa que a dividia em lotes, com a aprovação do Incra, e vendia aos chamados colonos, frequentemente vindos da Região Sul do país. Outra forma assumida por essas ações de reocupação foram os projetos agropecuários, quando grandes quantidades de terra eram entregues a empresas para o desenvolvimento dessas atividades (os dados mostram que, em mais de $90 \%$ dos casos, elas se restringiam à criação de gado). Em todas essas ações, a população local, formada por posseiros, garimpeiros, povos indígenas, foi ignorada.

Diante da dificuldade de acesso ao noroeste do estado, que ficava fora da área de influência das Rodovias Federais 364 e 163, a região não atraiu projetos de colonização particulares imediatamente. Seu isolamento em termos de acesso e comunicação foi uma de suas fortes características. A densidade demográfica dessa área, em 1980, por exemplo, era de apenas $0,14 \mathrm{hab} . / \mathrm{km}^{2}$, conforme constata Joanoni Neto (2008, p. 51), com dados do DNPM em Mato Grosso.

Juína foi um dos 14 projetos coordenados pelo estado de Mato Grosso naquele período. No início dos anos 1970, uma série de ações conjuntas entre governo estadual e federal começou a inserir uma nova dinâmica à região, caracterizando o início da construção de uma frente pioneira. Em 1972, por meio da Lei $\mathrm{n}^{\circ} 3.307$, de 18 de dezembro, o governo do estado de Mato Grosso reservou extensas áreas de terras devolutas da região à Codemat, com a finalidade de desenvolver projetos de colonização. O projeto Juína nasceu em 1976 e foi aprovado pelo Incra em 17 de setembro de 1978, por meio da Portaria 907. Em 10 de junho de 1979 , a Lei ${ }^{\circ} 4.038$ criou o distrito de Juína, e, em 9 de maio de 1982, a Lei $n^{\circ} 4.456$ desmembrou Juína da área pertencente a Aripuanã, reconhecendo essa nova unidade municipal.

O projeto Juína foi considerado bem-sucedido, pois os lotes urbanos e rurais foram rapidamente vendidos. A propaganda realizada na Região Sul do Brasil traçava perfil promissor do noroeste do estado de Mato Grosso, o que, sem dúvida, teve importância fundamental no sucesso do empreendimento imobiliário. Na edição de 7 de abril de 1978, o jornal A Folha de Londrina anunciou os encantos do projeto, falava da localização privilegiada no centro do país, das terras férteis, do potencial para o setor madeireiro, vendendo, dessa forma, os sonhos de muitos agricultores e trabalhadores em dificuldades no Sul e Sudeste do 
país. A propaganda contribuiu para que os lotes rurais fossem rapidamente vendidos, a área do projeto (400 mil hectares) foi reocupada, as primeiras casas foram construídas no núcleo urbano, as estradas foram abertas, mesmo com a falta de infraestrutura e as demais dificuldades de abastecimento, atendimento de saúde e educação.

Em 1987, tornaram-se conhecidas as notícias da existência de ricas jazidas de diamantes no território destinado para colonização e produção agrícola:

A notícia do potencial diamantífero ultrapassou as fronteiras mato-grossense e brasileira, tornando Juína mundialmente conhecida por possuir, senão a maior, uma das maiores jazidas do mundo e segundo estimativa de técnicos de uma multinacional que aqui minerou (The Beers International) a exploração estaria garantida por 50 anos (ALMEIDA, 2002, p. 16).

Em função da fama de possuir uma das maiores reservas de diamantes do mundo, a partir de 1987, Juína começou a receber um quantitativo de garimpeiros extraordinário, no entanto, difícil de precisar em função da dinâmica de deslocamento dessas pessoas entre as frentes de trabalho. A chegada dos garimpeiros produziu grandes impactos na região e no projeto de colonização.

Dentre os impactos, destaca-se o surgimento de diversos núcleos garimpeiros ao longo dos pontos de extração do minério, em especial no quadrante sudoeste do município, ao longo do curso do Rio Cinta Larga, acompanhando a estrada vicinal denominada linha 3, que dava acesso ao distrito de Terra Roxa, distante cerca de 60 quilômetros do núcleo urbano do projeto Juína.
Após a dispersão das boas novas que anunciavam o potencial de riquezas contidas no subsolo da região, as currutelas garimpeiras começaram a brotar por toda região. Em poucos meses, diversas áreas eram exploradas pelos garimpeiros, manualmente ou com a utilização de maquinários (SANTOS, 2012, p. 115).

Ao longo da Rodovia MT 174, que liga Juína, MT, a Vilhena, RO, dois grandes garimpos se formaram, o primeiro distante apenas 18 quilômetros do núcleo urbano de Juína, nas proximidades da junção dos Rios Juininha e Juína-Mirim, formou-se o garimpo do Juínão. No local não chegou a se formar uma currutela de maior expressão, pois, além da cantina que atendia às necessidades mais imediatas, a proximidade com o núcleo urbano facilitava a vida e a aquisição de gêneros diversos. $\mathrm{O}$ termo currutela é usado para designar um lugar de fixação, um ponto de referência, no qual se constroem moradias, no caso dos garimpeiros, provisórias, feitas com madeira bruta, palha e lona (material plástico de cor preta). Em meio a essas habitações, surgem pequenos comércios de viveres, combustível, bebida e prostíbulos. Sua existência é efêmera e sua população depende da "força" do garimpo.

Seguindo pela mesma rodovia em direção a Vilhena, RO, 60 quilômetros de distância do núcleo urbano, surgiu um dos mais expressivos garimpos da região: o garimpo do 180, por estar localizado no KM 180 da MT 174, divisa dos territórios indígenas Cinta larga e Enawenê-nawê. Nas margens da rodovia, logo surgiu uma representativa currutela. Esse garimpo estendeu-se pelas margens do Rio 21, que nasce em território Enawenê-nawê e deságua em terras Cinta larga. 
Dentre as diversas currutelas que se formaram, destaca-se a do Garimpo do Arroz, no curso da linha 3, na margem esquerda do Rio Cinta larga, a 10 quilômetros do distrito de Terra Roxa. Segundo estimativas não oficiais e relatos dos próprios garimpeiros, a currutela chegou a apresentar cerca de 5 mil habitantes.

O Arroz foi a mais complexa das vilas garimpeiras, surgiu logo após a tomada da área por garimpeiros, em conflito com a mineradora Itapená (multinacional francesa), rapidamente os garimpeiros que mineravam na região presenciaram e promoveram o surgimento de instalações e estabelecimentos, dignos de uma vila que aos olhos de muitos, caminhava para constituição de uma futura cidade. Em poucas semanas, a antiga plantação de arroz que dava nome ao local, foi devastada pelos garimpeiros (SANTOS, 2012, p. 121).

De acordo com esses relatos, havia ainda três farmácias, dois açougues, uma sorveteria e várias mercearias, além disso, havia no local até mesmo um dentista.

Tinha na base de mil a mil e quinhentos metros de barracos dos dois lados da estrada. À tardezinha e noite aquilo fervia, tinha muito peão rodado e tinha muita mulher que era de todo mundo, às vezes o peão achava que era só dele e ficava enciumado, toda semana era na base de 6 a 8 mortos, aqueles "catriados" estão cheio de ossada de peão (SOUZA, 2010, não paginado).

Peão rodado é a designação dada ao trabalhador braçal que realiza tarefas em regime de informalidade. É chamado de "rodado" por não ter uma residência fixa e ficar andando de uma empreita para outra. Catreado ou catriado é o nome das valas que se abriam durante a extração do minério.
Estabelecimentos com presença marcante na currutela do Arroz eram as casas de prostituição, os "cabarés" ou, como muitos garimpeiros preferiam denominar, as "zonas". A abundância de meretrizes, bebidas, jogatina e dinheiro proveniente da venda das pedras, associada à presença incipiente do Estado, como normalmente ocorre em regiões de garimpo, tornou o cotidiano desafiador do ponto de vista das relações sociais, em razão da recorrência dos atos de violência. O espaço do meretrício nas áreas de garimpo é historicamente marcante, é difícil imaginar uma currutela garimpeira sem tal prática. Ao analisar o espaço da mineração na primeira metade do século XX, Regina Beatriz Guimarães Neto faz essa constatação:

Todavia, os espaços delimitados como áreas de meretrício - fronteiras fluídas - sobressaem, de forma especial, na paisagem de qualquer cidade ou povoado minerador, fazendo parte incontestável das representações sobre os garimpos. Inúmeros casos são relatados sobre crimes, tiroteios, paixões de toda espécie, num jogo mítico de cobiça e sedução (2006, p. 137).

Fato é que a prática da violência se tornou algo comum nesse espaço. Como geralmente ocorre nos ambientes dos garimpos, durante às noites, os atos de violência eram mais frequentes, pois durante o dia os garimpeiros estavam trabalhando nos catriados das proximidades da currutela. Os bares e os prostíbulos eram os locais em que se podia beber, conversar, passar o tempo. O consumo exagerado de bebidas alcoólicas ensejava desentendimentos, brigas, discussões, que podiam terminar em ferimentos e mortes. 
Durante o dia era tranquilo, mas a noite ficava igual vespeiro, daqui pra lá era só zona de um lado. A noite carro tinha que ir devagar, porque era igual vespeiro, todo mundo armado, uma vez só, vi três mortos [...] quando tinha desavença com alguém um não esperava o outro, porque sabia que ia morrer (SOUZA, 2010, não paginado).

Ainda no ano de 1988, os jornais locais denunciavam as constantes mortes que ocorriam nos garimpos:

Nosso garimpo está "movimentadíssimo". O diamante está com um bom preço mesmo! Só que [...], brevemente irá faltar caixão fúnebre e munição nas lojas da cidade. Ah! E tem mais, lá tem até lista negra exposta ao público. ${ }^{1}$

Cabe esclarecer que esses jornais tiveram existência curta, alguns circularam poucos meses, com diagramação e impressão rudimentar, artigos não assinados, formatos variados. Apesar disso, são importantes registros sobre o modo como aquelas pessoas se viam e viam seu entorno.

No auge da atividade garimpeira, em 1989, segundo depoimentos, as práticas de violência foram mais frequentes, alguns relatos impressionam pela brutalidade e pela frieza com que se matava:

[...] tinha um rapaz chamado Maranhão, ele foi beber numa casa lá pra baixo, chamada "rabo de bica", deram uma facada nele lá! Aí ele veio correndo até chegar no meu bar. Quando ele chegou, ele gritou, mas gritou, já assim bem roco, eu "escutei" aquele vulto assim: "Preta! Dona Preta! Preta!". No que eu saí: - É o Maranhão que tá chamando a senhora. Ele caiu bem dentro assim do meu bar, quase assim na porta da lanchonete. E quando eu olhei, tava o coração dele! Eu vi o coração dele fazendo assim, sabe, aquele sangue? Então aquilo me marcou demais, o cara meteu a faca e fez assim com a faca, sabe? No coração dele! Então essa morte até hoje! [...] Ah, ali, pra "mim" ser sincera, diz que foi por causa de mulheradas, né! Ciúme, você sabe como que é! E foram muitos, muitas e muitos que morreram! Que viviam nessa vida e morreram. Então eu creio, eu acredito que Deus sempre esteve comigo, sempre me livrou! Porque hoje eu estou aqui contando, hoje eu estou aqui graças a Deus! Toco um comércio com as graças de Deus! Eu não vendo nem bebida pra ser sincera! Não vendo bebida! Não vendo cigarro! Não vendo baralho! Nada daquilo que me prejudicou, que eu prejudiquei... que vi muita gente prejudicada por causa de bebidas, nas mesas de jogos com bebidas, morte [...] (FARIA, 2012, não paginado).

Finalmente, os roubos e furtos aparecem como terceira causa da violência nesses espaços, quase sempre punidos com a morte, e isso era algo quase natural. Matava-se muito por mulheres, por bebidas, por roubos, mas tudo que provocasse desagrado ou colocasse em dúvida a honra do outro, atrapalhasse seu trabalho ou, de alguma forma, fosse interpretado como desrespeito era pretexto para violência.

Era mulherada e roubo também tinha muito que falar: "Não é porque roubou no garimpo, é porque roubou de fulano [...]. Aconteceram muitas mortes por roubo, mas, mais, mais mesmo era por mulherada, sabe? Aquelas mulheres assim sem sentimentos também, que queria só dinheiro dos homens [...] que quando estava com dinheiro tudo bem, você saía, chegava outro, já tinha abandonado e você não tinha aquela opinião de estar aceitando, até porque ela tava naquela vida dela lá, o garimpeiro se apaixonava, bebia, bebia e depois você sabe! Então a maioria das mortes era isso, era mulher e roubo (FARIA, 2012, não paginado).

Nas entrevistas, é relatada com muita frequência e naturalidade a morte de ga- 
rimpeiros em razão de desentendimentos ocorridos dentro dos garimpos. Segundo os relatos, os autores dos crimes raramente eram denunciados, uma "lei" do garimpo é a de que não se denunciava o executor, tudo era feito em público, mas, quando a polícia chegava, ninguém testemunhava, por medo, mas também em razão do perfil dos envolvidos. Essas pessoas mal se conheciam ou se relacionavam, trabalhavam e viviam por si, e nas breves passagens pelas currutelas não desenvolviam vínculos de amizade ou afetivos. A tensão gerada pela incerteza do alcance dos objetivos de cada uma das frentes de trabalho no garimpo, as disputas por mulheres nos cabarés, o desconhecimento da origem do outro, dentre vários outros fatores, traziam para as currutelas e para o garimpo condições de instabilidade social e de incerteza, produzindo um ambiente com comportamentos divergentes e instáveis.

Outro fato notável era a recusa dos taxistas e fretistas (proprietários de caminhões, pick-ups ou de outro veículo que pode ser fretado), em socorrer os garimpeiros baleados ou esfaqueados, ainda com vida. Como o hospital mais próximo ficava no núcleo urbano, quando esses proprietários realizavam a corrida, ficavam na incerteza do recebimento, portanto, a menos que algum conhecido pagasse pelo serviço de transporte adiantado, o socorro era recusado.

Tal contexto tinha a seu favor a presença incipiente de agentes públicos. Um território de ilegalismos, regido mais pelas convenções do garimpeiro do que pelas leis do Estado. Robert King Merton (1970) fala em estado de anomia social, conceito utilizado para definir ambientes sociais caracterizados por degradação, carência ou ausência das normas sociais. Para Merton (1970), a atenuação dos meios legítimos leva a sociedade à instabilidade, caracterizando o estado de anomia. $\mathrm{O}$ fracasso nas tentativas de legitimação de poderes sobre as currutelas deixava essa sociedade em condições de anomia aguda, que é a amplificação do processo de desvios de conduta. Houve mais do que uma desintegração dos sistemas de valores compartilhados socialmente, houve a banalização da violência. No entanto, no universo dos garimpos tradicionais, existem códigos de conduta próprios e característicos.

Entre os garimpeiros, existem algumas crenças, como a de que não se deve guardar o que se ganha, a de que é preciso esbanjar para que a sorte não lhes abandone e a de que, para que a terra dê o que tem (ouro ou diamante), é preciso jorrar sangue sobre ela. Os garimpeiros não sabem explicar a origem dessas crendices, mas sua presença é marcante entre eles. Muito se gasta com bebidas e prostituição, mas também é fato que a sobrevivência custa absurdamente caro, tornando ilusórios os aparentes altos ganhos com o garimpo. Esses são espaços de sonhos, esperanças e oportunidades. $\mathrm{O}$ sonho de encontrar uma grande pedra, ou da "bamburra", a esperança do enriquecimento rápido, das oportunidades de negócios entre comerciantes, prostitutas e outros prestadores de serviços. Os preços praticados nos garimpos não mantêm conexão com o mundo fora da currutela. Eles possuem lógica 
própria, dada pelas distâncias, pelas dificuldades de transporte, pela alta procura, pelos grandes riscos que qualquer negócio enfrenta nessas áreas. As condições gerais do universo do garimpeiro acabam por constituir uma imagem de homem rude, supersticioso, violento e perigoso:

São algumas "verdades" constituídas a partir de múltiplas coerções, num regime de poder próprio de cada sociedade, que aparecem quase sempre associadas aos trabalhadores pobres como se surgissem da "natureza", destituindo-as de fundamento histórico (GUIMARÃES NETO, 2006, p. 141).

Assim, em diversos relatos, depoimentos e artigos de jornais, aparece uma representação constituída a partir da visão do outro, que, em geral, denigre a imagem do garimpeiro, sem levar em consideração o processo histórico e o ambiente social que forjaram suas condições de vida e suas crenças. Tratamos, portanto, de uma fronteira não apenas geográfica, mas, principalmente, que se coloca entre "o eu e o outro". Para Guimarães Neto, a atividade mineradora, pelas possibilidades que oferta a homens expropriados, revela-se como fundadora de novos povoados. São comunidades em formação, nas quais a violência está presente, até que um conjunto de regras sociais se constitua com poderes legitimados.

No caso das currutelas garimpeiras de Juína, tais espaços não chegaram a constituir uma comunidade organizada e estabelecida, elas declinaram junto com a queda na produção, com as flutuações no valor comercial dos diamantes no mercado internacional e com a proliferação dos casos de malária. A violência fez parte do cotidiano dessas pessoas, "assim, garimpo, prostituição e violência aparecem como parte de uma relação que se apresenta de forma indissociável" (GUIMARÃES NETO, 2006, p. 141).

A presença esporádica da polícia nas vilas garimpeiras (frequentemente restrita a dois homens), geralmente apenas quando aconteciam os assassinados, também não chegou a regular qualquer conduta social nesse ambiente. Não houve, nos garimpos, a legitimação de poderes representativos do Estado, prevaleceram a prática da "justiça com as próprias mãos" e a "lei do silêncio".

Nos garimpos da linha 3, as marcas da ausência de um poder estabelecido e legitimado estão por toda parte. Além das situações corriqueiras citadas anteriormente, a Revista Tribuna de Juína publicou:

A ocupação caótica refletiu-se na falta de planejamento, a inexistência de um projeto de iniciativa de desenvolvimento e milhares de brasileiros aqui aportaram, seduzidos pela promessa de enriquecimento fácil através do diamante. ${ }^{2}$

A ocupação foi muito rápida e caótica, as currutelas garimpeiras não possuíam nenhum tipo de infraestrutura, a começar pelas moradias, quase sempre de madeira e cobertas com folhagens e lonas, eram denominadas pelos próprios garimpeiros de barracos, não havia nenhum tipo de acesso a um sistema de saúde. Em caso de enfermidades ou acidentes, os pacientes precisavam ser levados para o hospital mais próximo, no núcleo urbano de Juína, 60 quilômetros dali, por uma estrada de terra constantemente esburacada e/ou, no tem- 
po das chuvas, enlameada e com frequentes atoleiros. Quando essas currutelas duravam mais tempo, entre dois e cinco anos, era comum haver crianças que demandavam educação formal. No caso do Garimpo do Arroz, a escola funcionou na própria currutela, em barracos de lona, com salas multisseriadas e professores leigos.

No que se refere à violência em sua forma mais evidente, na física de "um contra o outro", os relatos indicam ações quase cotidianas de conflitos, mortes e agressões por armas de fogo e armas brancas. Três fatores são apontados, de forma unânime, como amplificadores da violência. O primeiro era o constante consumo de bebida alcoólica pelos garimpeiros, durante o trabalho, para suportar as péssimas condições, que os obrigavam a permanecer dentro d'água, desde a madrugada até o entardecer, e nos bares e zonas da currutela, durante a noite. A permanência nesses espaços, durante o dia, ficava restrita aos homens que estavam sem lugar para trabalhar, o que podia ocorrer com alcoólatras, convalescentes da malária ou outro mal e recém-chegados, que procuravam esses locais para fazer contatos.

O segundo fator apontado era a prostituição. O garimpo era um ambiente predominantemente masculino, e a forma de suprir a escassez da figura feminina era a existência das casas de prostituição. Muitas vezes, o garimpeiro, tal como o peão rodado, que vinha sozinho de outras regiões (era comum que tivessem mulher e filhos em outro lugar), acabava se envolvendo com uma dessas profissionais do sexo. A única forma de manter exclu- sividade sobre ela era produzir o bastante no catreado para sustentá-la. Quando isso não acontecia, ela se via na contingência de aceitar programas com outros garimpeiros. Essas mulheres eram trazidas por proxenetas, que as exploravam em troca de abrigo, alimentação e "segurança" (essa relação era frequentemente muito violenta, e as denúncias de meninas menores de idade sequestradas eram frequentes). Esse tipo de situação gerava graves conflitos.

Na visão de Arendt, não existe poder nas passagens e no modo de vida social que acabamos de descrever, pelo contrário, há ausência dele. Para a autora, poder se caracteriza pela habilidade humana de agir em concerto:

O poder corresponde à habilidade humana não apenas para agir, mas também para agir em concerto. O poder nunca é propriedade de um indivíduo; pertence a um grupo e permanece em existência apenas enquanto o grupo permanece unido (ARENDT, 2009, p. 60).

De acordo com Martins (2009), a fronteira é espaço de degradação do outro. O espaço caracterizado como frente de expansão é conflituoso, difícil e precário, no qual nem sempre é possível definir a fronteira entre o que é legítimo e o que é ilegal, um convite às práticas de violência. Quando a atividade garimpeira é inserida neste já complicado processo, os desafios se tornam ainda maiores, e, no caso de Juína especificamente, o resultado é uma coletividade formada por diversos grupos, com interesses diversos.

Nas currutelas garimpeiras, os grupos se encontravam e se separavam com 
uma rotatividade incrível, em geral, não se constituíam laços maiores ou relações duradouras, não se apresentava preocupação com a origem do indivíduo, muitas vezes, o sujeito era identificado apenas por apelidos, como "Baiano", "Ceará", "Paraíba". Ser chamado apenas pelo apelido garantia o anonimato aos que traziam consigo pendências com a lei. Eram homens que viviam migrando entre as "fofocas" (áreas nas quais se afirmava haver ouro ou diamante), sem vínculos pessoais, com suas posses reduzidas a um embornal, "boróca", na qual levavam todos os seus pertences. Esses sujeitos passavam a usar um apelido em lugar do nome, vivendo sem qualquer expectativa, não raro, fugindo do próprio passado, escondendo-se de si mesmos. A busca pela grande pedra ou pepita era o sonho que alimentava seus dias de trabalho duro no catreado e que se esgotava em si.

Para Martins, a exploração de possibilidades diversas, do ponto de vista da pesquisa histórica,

[...] também é cenário privilegiado de observação sociológica e conhecimento sobre os conflitos e dificuldades próprias da constituição humana do encontro de sociedades que vivem no limite e no limiar da história (2009, p. 96).

Nessa perspectiva, a fronteira abre um universo de possibilidades, que enriquecem a análise, contribuem conceitualmente para a relação da infinidade de fatos conflituosos, situações de imposição por meio da violência que estão diretamente relacionas com prostituição, mortes e miséria humana. Por fim, no caso de Juína, como em outros locais, tais como Alta
Floresta, por exemplo, a presença desse grupo social formado por garimpeiros interferiu no projeto inicial de formação de uma sociedade agrária industrial, aspecto que, muitas vezes, é visto como ameaça ao projeto original. A descoberta de riquezas minerais nas áreas controladas pelas empresas privadas de colonização, em alguns casos, não foi vista com simpatia. Não foi esse o caso de Juína, onde a elite local tirou o máximo de proveito da situação, tentando manter o controle sobre a atividade e até mesmo sobre os garimpeiros.

Se pensarmos as ações coordenadas de tentativas de formação de sindicato dos garimpeiros de Juína, no ano de 1989, dirigidas pelas autoridades locais e promovidas por integrantes da elite local, como o mais próximo que esses trabalhadores chegaram a ter sua atuação e ações inseridas na lógica da legitimação e obediência, por meio de uma instituição registrada nos órgãos de governo que regulariam sua atividade, é possível perceber o nível de fragilidade das relações institucionais estabelecidas nesse ambiente.

Convoca-se todos os garimpeiros, faiscadores e interessados em criar o sindicato dos Garimpeiros de Juína, para a Assembleia de sua constituição (fundação), a realizar-se em: Data: 10 de maio de 1989, Local: Juína Clube às 9h. Com os seguintes assuntos: Análise e aprovação do estatuto social, Eleição da diretoria, Assuntos gerais. ${ }^{3}$

A ação poderia ser interpretada como uma tentativa dos próprios garimpeiros de lutar por direitos pelo reconhecimento da instituição sindicato pelo Estado e, consequentemente, de novos padrões de relações, no entanto, o propósito estava 
distante disso. A edição do mesmo jornal da segunda quinzena de maio anunciou o resultado da reunião. Foram eleitos, para a diretoria do sindicato, empresários e políticos locais, donos de propriedades que enxergaram no garimpo uma boa oportunidade para ampliar suas posses. $\mathrm{O}$ sindicato nunca prosperou.

O complexo processo de reocupação foi atravessado pela atividade garimpeira, que, na visão da maioria dos entrevistados, foi fundamental para a economia da cidade de Juína, principalmente em função do contexto de crise do projeto agrícola, ao passo que potencializou os problemas de infraestrutura (hospitais, estradas, escolas, etc.), em função do aumento da demanda no atendimento gerada pelo garimpo, sem considerar a amplificação das práticas de violência e outros efeitos sociais. Por exemplo, não era incomum que garimpeiros mantivessem casos amorosos com moradoras locais e que, desses relacionamentos, nascessem filhos. Quando a atividade garimpeira enfraquecia, esse homem migrava e deixava para trás os filhos do garimpo, para reproduzir uma expressão usada por uma professora naquela cidade.

O aparentemente novo da fronteira é, na verdade, expressão de uma complicada combinação de tempos históricos em processos sociais que recria formas arcaicas de dominação e formas arcaicas de reprodução ampliada do capital (MARTINS, 2009, p. 12).

Nesse sentido, diante do garimpo, a colonização foi redesenhada, os limites e as possibilidades redefinidos, e a esperança, para muitos, foi renovada.
O pensamento de Arendt contribui, neste estudo, para a diferenciação entre poder e violência, uma vez que sua perspectiva possibilita algumas reflexões relacionadas às sociedades mineradoras. A diferenciação conceitual entre poder e práticas coercitivas violentas e a forma como elas se afastam e se aproximam são fundamentais para a compreensão da dinâmica de poder e violência nos garimpos, neste caso, principalmente para compreendermos a dinâmica social e histórica de um espaço no qual a frente pioneira se mistura com o espaço de expansão e o contingente de garimpeiros. Arendt (2009), questiona a associação do conceito tradicional de poder e das práticas coercitivas, especialmente no sentido de violência. Em síntese, para a autora, a violência se manifesta em situações-limite, nas quais o poder não é mais eficaz ou não chegou a se constituir de forma legitimada, como é o caso dos ambientes dos garimpos de Juína e das currutelas garimpeiras e mineradoras. Para a filósofa alemã, poder é, antes de tudo, uma relação consensual de comando e obediência, portanto não há coerção nas relações de poder, ele é legitimado pelo consentimento de quem obedece.

É a partir da ênfase na questão da legitimidade do poder efetivado em atos e palavras não violentos que o fenômeno da obediência às leis e às instituições políticas de um país pode ser compreendido e diferenciado em relação àquela obediência que é extorquida sob a ameaça da coerção, da punição ou mesmo da violência (ARENDT, 2009, p. 147).

O poder, portanto, para Arendt, é uma relação legítima, consentida, diferente da 
violência, que se manifesta diante da ausência dele. Esse entendimento é fundamental para compreendermos que, nas sociedades em formação, como é o caso das cidades colonizadas a partir da década de 1970, no norte e noroeste de Mato Grosso, a presença incipiente do Estado produziu um ambiente de predominância das práticas de violência, em detrimento das relações de controle e obediência ou consentidas, até que a institucionalização do poder público legitimasse as relações sociais gradativamente.

De acordo com Arendt, apesar de se correlacionarem, os dois termos são equivocadamente utilizados como sinônimos, por essa razão, ela explica que

[...] é particularmente tentador pensar o poder em termos de comando e obediência e assim equiparar poder e violência. [...]. É como se violência fosse um pré-requisito do poder, e o poder nada mais do que uma fachada (2009, p. 143).

\section{Resumen}

Este artículo realiza una discusión inicial acerca de las relaciones de poder y de la violencia en las áreas fronterizas reubicadas por diferentes grupos sociales, tales como, mineros tradicionales, prostitutas, peones y comerciantes en los espacios de los garimpos, constituidos a partir de los descubrimientos de yacimientos diamantíferos en el municipio de Juina, de los años de 1987 y 1994. El poder es comprendido como relación legítima de mando y obediencia al paso que la violencia es pensada como instrumento de dominación e imposición sobre el otro en lugares cuya presencia del Estado es incipiente. Weber y Arendt son importantes referencias para el diálogo de la relación entre poder y violencia. La frontera es pensada en la lógica de los frentes de expansión y pionera de José de Souza Martins. El recurso de la historia oral fue utilizado para recuperar relatos de violencia en esos espacios, en especial en lo Garimpo del Arroz.

Palabras clave: Frontera. Garimpos. Violencia.

\section{Abstract}

This article presents an initial discussion about the power relations and violence in the frontier areas reoccupied by different social groups, such as, traditional miners, prostitutes, unskilled worker and merchants in the spaces of the garimpos (the place where the ore is explored), constituted from the discoveries of diamond deposits in the municipality of Juína, Northwest of Mato Grosso, Brazil, between 1987 and 1994. Power is understood as a legitimate relation of command and obedience while violence is thought as an instrument of domination and imposition on the other in places where the presence of the State is incipient. Weber and Arendt are important references for the dialogue of the relationship between power and violence. The frontier is thought of in the logic of fronts of expansion and pioneer of Martins. The oral history resource was used to recover reports of violence in these spaces, especially in the place called Garimpo do Arroz.

Keywords: Violence. Garimpo. Frontier. 


\section{Notas}

1 Jornal O Imparcial, Folha do Nortão, ano $1, \mathrm{n}^{\mathrm{o}} 4$, jornal quinzenal outubro de 1988.

2 Revista Tribuna de Juína, ano I, Edição Especial, p. 21, maio de 1995.

3 Jornal O Imparcial, Folha do Nortão, ano 1, $\mathrm{n}^{\circ} 14$, abril de 1989.

\section{Referências}

ALMEIDA, Cléia de. Educação em áreas de garimpo. 2002. 56 f. Trabalho de Conclusão de Curso (Licenciatura em História) - Curso de História, Universidade Federal de Mato Grosso, Juína, 2002.

ARENDT, Hannah. Eichmann em Jerusalém: um relato sobre a banalidade do mal. São Paulo: Companhia da Letras, 1999.

. Sobre a violência. Rio de Janeiro: Civilização Brasileira, 2009.

BOBBIO, Norberto. Dicionário de política. Brasília: UnB, 1993.

CAMPOS, Pedro Humberto Faria; GUIMARÃES, Silvia Pereira. Sociabilidade violenta: contemporaneidade e os novos processos sociais. Estudos, Goiânia, v. 35, n. 5, p. 901-913, set./out. 2008. Disponível em: <http://seer. pucgoias.edu.br/index.php/estudos/article/ view/1100>. Acesso em: 18 jan. 2018.

FARIA, Ilmar. Entrevista. Terra Roxa, Juína, MT, 26 jun. 2012.

GUIMARÃES NETO, Regina Beatriz. Cidades da mineração: memórias e práticas culturais. Mato Grosso na primeira metade do século XX. Cuiabá: EdUFMT/Carlini \& Caniato, 2006.

JOANONI NETO, Vitale. Juína: de projeto de colonização a polo regional. In: BARROZO, João Carlos (Org.). Mato Grosso: do sonho à utopia da terra. Cuiabá: EdUFMT/Carlini \& Caniato, 2008. p. 15-26.
MARTINS, José de Souza. Fronteira: a degradação do outro nos confins do humano. São Paulo: Contexto, 2009.

MERTON, Robert K. Sociologia: teoria e estrutura. São Paulo: Mestre Jou, 1970.

MICHAUD, Yves. A violência. São Paulo: Ática, 1989.

MORENO, Gislane. O processo histórico de acesso à terra em Mato Grosso. Geosul, Florianópolis, v. 14, n. 27, p. 67-90, 1999.

MÜLLER, Jean-Marie. O princípio da não-violência: uma trajetória filosófica. São Paulo: Palas Athena, 2007.

RIBEIRO, José Donizete. Terra e garimpos: um estudo da violência nos anos de consolidação do espaço da colonização. 2002. 231 f. Dissertação (Mestrado em História) - Programa de Pós-Graduação em História, Universidade Federal de Mato Grosso, Cuiabá, 2002.

SANTOS, Júlio Cesar dos. Garimpos de Juína: entre histórias, relatos e memórias. 2012. 166 f. Dissertação (Mestrado em História) - Programa de Pós-graduação em História, Universidade Federal de Mato Grosso, Cuiabá, 2012.

SOUZA, Edevaldo. Entrevista. Juína, MT, 10 nov. 2010. 